\section{Parkinson's Disease and Movement Disorders: Diagnosis and Treatment Guidelines for the Practicing Physician}

by Charles H. Adler and J. Eric Ahlskog, 474 pp, ill, Totowa, NJ, Humana Press, 2000, $\$ 99.50$

Movement disorders specialists are masters of minutiae. There is nothing they like more than obsessing over whether a particular clinical phenomenon represents a tic, tremor, stereotypy, mannerism, or myoclonus. This is the modus vivendi of the movement disorder specialist. But for the rest of us, for whom the basal ganglia and associated clinical syndromes represent the "dark basements of the brain" and who do not feel all that comfortable in such dimly lit basements, this book demystifies, enlightens, and educates. The editors requested all chapter authors to imagine they were teaching during a preceptorship in their clinic, with the goal of "offering the reader full confidence in approaching patients with movement disorders." The result is an outstanding accomplishment.

The book is organized into five sections: basic diagnostic principles, PD, other parkinsonian states, hyperkinetic movement disorders, and other movement disorders. In all, 12 chapters are devoted to PD, including excellent summaries on pathophysiology and genetics, although the focus of the book throughout is on diagnosis and management. There are excellent chapters on sleep disorders, autonomic and psychiatric complications in PD, as well as nonpharmacologic therapies for PD. Separate chapters are devoted to gait disorders and restless legs syndrome. The chapter on psychogenic movement disorders is most insightful.

Despite contributions from 35 authors, the style is uniform and the text reader-friendly, although the chapter on speech disorders is perhaps too detailed for the scope of the book. The text is punctuated with useful tables, but the clinical descriptions and practical approach to patient management are what make this an exceptional text. General neurologists, movement disorders fellows, and internists will all find this book an excellent resource.

Timothy Counihan, MD, MRCPI

Copyright $($ C) 2001 by AAN Enterprises, Inc.

\section{Alzheimer Disease: The Changing View}

by Robert Katzman and Katherine Bick, 255 pp, ill, San Diego, CA, Academic Press, 2000, \$69.95

In his introduction to Memoirs of a Geisha, Arthur Golden observes that "a memoir provides a record not so much of the memoirist as of the memoirist's world." This is the type of record Drs. Robert Katzman and Katherine Bick have strived to create in Alzheimer Disease: The Changing View. This book captures the reminiscences of 22 scientists, clinicians, policy makers, and lay persons who participated in an early phase (1960 to 1980) of the modern war against $\mathrm{AD}$.

The period in question represents a time of transition in public and professional attitudes about $\mathrm{AD}$, a time when many of the foundations of modern-day Alzheimer research, clinical practice, and public policy were first laid out. It is the period in which $\mathrm{AD}$ was recognized as a leading cause of dementia in elderly, ultimately eclipsing "hardening of the arteries" for that title. This is the era in which the cholinergic theory of $\mathrm{AD}$ causation took root, setting the stage for the current generation of symptomatic pharmacotherapy. During this period, the Alzheimer Association took its first formative steps toward becoming the most influential
Alzheimer advocacy organization in the United States. Federal government funding for dementia research was minimal during that era, but expanded dramatically in its aftermath. The recollections of 22 people who were intimately involved in these events provides an interesting perspective on how they and the rest of the world viewed $\mathrm{AD} 20$ to 40 years ago.

The authors are imminently qualified to write on this subject. Dr. Katzman is widely recognized as one of the central figures of $\mathrm{AD}$ clinical practice and public policy during the period in question. His 1976 editorial on the subject stimulated the interest of the medical and scientific communities and led to the first NIH consensus conference on $\mathrm{AD}$. He and several of the others interviewed in this book played a role in the organization of the Alzheimer Association in the United States, as well as innumerable other Alzheimer-related initiatives. Dr. Bick is a former deputy director of NINDS and deputy director of NIH for extramural research. She possesses a broad perspective on US research and health care funding policy as it relates to $\mathrm{AD}$, as well as a detailed knowledge of Dr. Alzheimer's own work. These two authors each interviewed roughly half of the contributors and took turns interviewing one another. Although neither can be characterized as a professional biographer, their first-hand knowledge of the period in question and of the individuals they interview enriches the book's content considerably.

The interviews are grouped into chapters entitled "The Pioneers" (Robert Terry, Michael Kidd, Martin Roth, Bernard Tomlinson, Garry Blessed), "The Need for Care" (Elaine Brody, Powell Lawton), "Understanding the Biology of AD" (Henry Wisniewski, Leonard Heston), "The Cholinergic Story: Hope for the Patient and Family" (David Drachman, David Bowen, Elaine and Robert Perry, Peter Davies), "Improving the Accuracy of Diagnosis" (Paul McHugh, Mashall Folstein) and "The Impact of AD and Society's Response (David Kay, Robert Katzman, Robert Butler, Katherine Bick, Lonnie Wollin, Hilda Pridgeon, Jerome Stone). An introductory chapter ("Setting the Stage") provides historical perspective, whereas the final chapter ("The Next Act") provides a brief sketch of advances since 1980. With the exception of the first and last chapters, which are written in prose and include references, the book is composed entirely of transcribed interviews averaging 10 to 20 pages in length with brief biographic introductions, printed in an unfortunately small font.

There is plenty of drama, intrigue, contentiousness, and even scandal in the Alzheimer field, but little of that can be found within the pages of this book. Instead, we encounter relatively restrained interviews, many of which are readable but few of which prove to be truly scintillating. Unlike true memoirists, these individuals have the benefit of knowing how things have turned out, and their recollections of the past are unavoidably biased by that knowledge. The interviews convey a generally positive impression of the contributors, but rarely, if ever, ask them to explore controversial topics. Most of the protagonists were asked to recount memories of their childhood, early schooling, and nonacademic life. This provides some sense of their origins and motivations for pursuing their particular career paths. Some of the more colorful moments include David Drachman's, explanation of how a colonic polyp was responsible for his decision to study memory, and Robert Terry's account of his battlefield experiences during World War II. In most instances, the early reminiscences contribute little toward the book's goals and would have been more productively edited out or summarized in the biographic introductions. Whereas the interviews succeed in bringing out a few interesting points about each person, there are few revelations that will be entirely new to Alzheimer-ologists. The book as a whole falls short of providing any major new historic insights that extend existing Alzheimer lore. 
This book provides first-person accounts of a relatively embryonic stage in the development of a field that has grown into a major medical/scientific enterprise. Having had the good fortune to know several of the talented individuals interviewed in this book, I found more than enough to hold my interest through its over 300 pages of text. I question whether an otherwise disinterested reader, or anyone but a student of the $\mathrm{AD}$ field, would be inclined to read this book cover-to-cover. It would appear that this book is written for present and future Alzheimer investigators, clinicians, policy makers, and historians. At one point, Katherine Bick discusses her studies of the publications of Dr. Alzheimer and his contemporaries, and observes:
I became so convinced that all the questions we were now asking were the same questions they had asked that it struck me that it was very important that we should try to make available/accessible to the modern investigators what their predecessors had said.

Therein lies the rationale for this book, and perhaps, a good reason to pay heed to the histories it contains.

Norman R. Relkin, $M D, P h D$

Copyright @ 2001 by AAN Enterprises, Inc.

\section{Corrections}

\section{Headache types and panic disorder: Directionality and specificity}

In the article "Headache types and panic disorder: Directionality and specificity" by Breslau et al. (Neurology 2001;56:350-354), an error in grant support was printed. The correct support information is as follows: Supported by NIH Headache Research Center grant P50 NS 32399, Bethesda, MD.

\section{Effect of aldose reductase inhibition on nerve conduction and morphometry in diabetic neuropathy}

In the article "Effect of aldose reductase inhibition on nerve conduction and morphometry in diabetic neuropahy" by Greene et al. (Neurology 1999;53:580-591), the incorrect table 5 was printed. The correct table 5 follows.

Table 5 Williams' test (three dose levels and one control)

\begin{tabular}{|c|c|c|c|}
\hline $\begin{array}{l}\text { Degrees of } \\
\text { freedom }\end{array}$ & Quantiles, \% & $\begin{array}{l}\text { Williams one-tailed } \\
\text { critical values }\end{array}$ & $\begin{array}{l}\text { Corresponding two-tailed } \\
p \text { values for } \mathrm{t} \text {-distribution }\end{array}$ \\
\hline 10 & 2.5 & 2.341 & 0.041269 \\
\hline 12 & 2.5 & 2.284 & 0.041378 \\
\hline 13 & 2.5 & 2.263 & 0.041401 \\
\hline 15 & 2.5 & 2.229 & 0.041528 \\
\hline 16 & 2.5 & 2.216 & 0.041536 \\
\hline 17 & 2.5 & 2.204 & 0.041596 \\
\hline 18 & 2.5 & 2.194 & 0.041603 \\
\hline 19 & 2.5 & 2.185 & 0.041619 \\
\hline 26 & 2.5 & 2.142 & 0.041731 \\
\hline 28 & 2.5 & 2.133 & 0.041829 \\
\hline 30 & 2.5 & 2.126 & 0.041847 \\
\hline 35 & 2.5 & 2.112 & 0.041896 \\
\hline 40 & 2.5 & 2.102 & 0.041897 \\
\hline 60 & 2.5 & 2.078 & 0.041996 \\
\hline 120 & 2.5 & 2.055 & 0.042050 \\
\hline
\end{tabular}




\section{Neurology}

\section{;Headache types and panic disorder: Directionality and specificity \\ Neurology 2001;56;1124 \\ DOI 10.1212/WNL.56.8.1124}

\section{This information is current as of April 24, 2001}

\section{Updated Information \&}

Services

Permissions \& Licensing

Reprints including high resolution figures, can be found at: http://n.neurology.org/content/56/8/1124.1.full

Information about reproducing this article in parts (figures,tables) or in its entirety can be found online at:

http://www.neurology.org/about/about_the_journal\#permissions

Information about ordering reprints can be found online:

http://n.neurology.org/subscribers/advertise

Neurology $®$ is the official journal of the American Academy of Neurology. Published continuously since 1951, it is now a weekly with 48 issues per year. Copyright . All rights reserved. Print ISSN: 0028-3878. Online ISSN: 1526-632X.

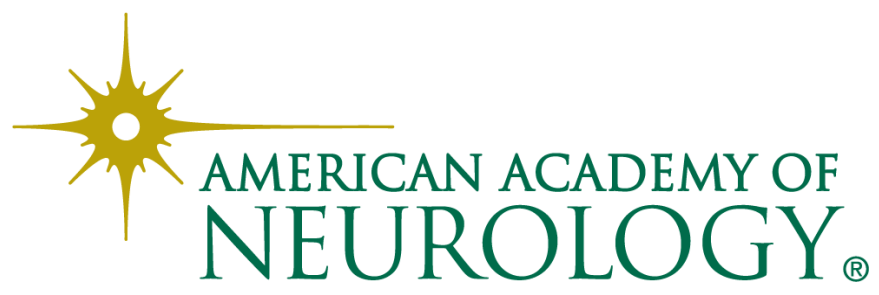

